societies is not exactly moved by rational arguments free from rhetoric and theatricality.

In the final analysis, when Einstein thought or spoke about democracy, he seemed to have focused on conditions for the freedom and creativity of the individual rather than the group. Hence, much more important than all the things he said and wrote was his personal example as a scientist. By demonstrating the powers of one person's mind to revolutionize the view of the cosmos, Einstein reaffirmed the value of free individual thinking in resisting group-mind and coerced opinion - and therefore sustained the possibility that the majority could be wrong.

Yaron Ezrahi is a professor of political science at the Hebrew University of Jerusalem, Mount Scopus, Jerusalem 91905, Israel.

\title{
Nervous systems made simple
}

\section{An Introduction to Nervous Systems by Ralph Greenspan \\ Cold Spring Harbor Laboratory Press: 2007. 200 pp. \$45, £26.99}

\section{Eve Marder}

Until I saw pieces of giant squid in a fish market in Chile, I somehow hadn't appreciated that giant squids were really giant. Ralph Greenspan's An Introduction to Nervous Systems will similarly enlighten many of its readers on the wonders to be found through the study of invertebrate nervous systems and the behaviours they control. Furthermore, it is an eloquent mixture of fundamental neuroscience and evolutionary biology. Greenspan uses a variety of invertebrate animals to describe the fundamental processes of nervous-system function and by placing the basics of neuronal signalling in their functional contexts, he casts this information in evolutionary terms.

The savvy and sophisticated neuroscientist will find themselves learning about evolution; the evolutionary biologist will be led through a remarkably clear exposition of ion channels and action potentials, the fundamental elements of nervous activity. Smart high-school students will find an accessible and engaging account that reveals the magic and mysteries of nervoussystem function in a wide range of animals. The book will be especially useful as a text for university-level courses wishing to provide students without previous knowledge of neuroscience a broad context with which to understand how nervous systems generate behaviour.

Greenspan manages to be a scholar without being a pedant. Each chapter, which starts with an apt quotation from the classics, has a specific focus, and examples are chosen with finesse. Greenspan introduces the fundamentals of ion-channel structure and function using the swimming behaviour of the unicellular Paramecium. He continues with the escape response of jellyfish and includes a remarkable tidbit of cellular electrophysiology that I was unaware of: jellyfish neurons that generate either a low-amplitude calcium-dependent or a highamplitude sodium-dependent action potential to trigger a slow or rapid behavioural response, respectively.

Greenspan introduces neuromodulation in the context of the behavioural sensitization of the gill-withdrawal response of the sea slug Aplysia californica. This is the famous preparation used as a paradigm to study simple forms of learning, and here is my first quibble. I am, perhaps wrongly, sceptical of the generality of the results that are used to argue that some species of mollusc fail to show behavioural sensitization. I wonder whether assaying a different behaviour might reveal sensitization in the species that don't show it using the methods so effective for A. californica.
Circadian rhythms, flight, navigation, decision-making, courtship and mating in Drosophila are used to introduce the structure and function of networks important for complex behaviours. These sections of the book are presented with enough detail to do justice to the interplay of physiological processes important for an animal to function in the real world. Greenspan's scrupulous respect for understanding an animal's nervous system in terms of its real-world behaviour is apparent in his discussion of honeybee learning, where he relates the probable connection between the timing of stimuli in honeybee learning and the nature of the bees' foraging behaviour.

Greenspan clearly intended this book to be readable by and accessible to anyone. He succeeds admirably and it is an unadulterated delight to read. However, I confess to a modicum of regret that to avoid interrupting the flow, the references are placed at the back of the book, without citing which experimental result is found in a given reference. This will require readers to dig a little (not such a bad thing) to find some of the papers that they might wish to look at more carefully.

In addition to its use as a textbook, this book would make a wonderful present for your lawyer, banker, doctor or musician friend who retains a genuine curiosity about how animals interact with the world. Alternatively, you can take it to the beach or mountains this summer and use it to remind yourself to watch all kinds of creatures in their natural settings - while they and their environments still exist on our planet.

Eve Marder is the Victor and Gwendolyn Beinfield Professor of Neuroscience at Brandeis University, Waltham, Massachusetts 02454-9110, USA.

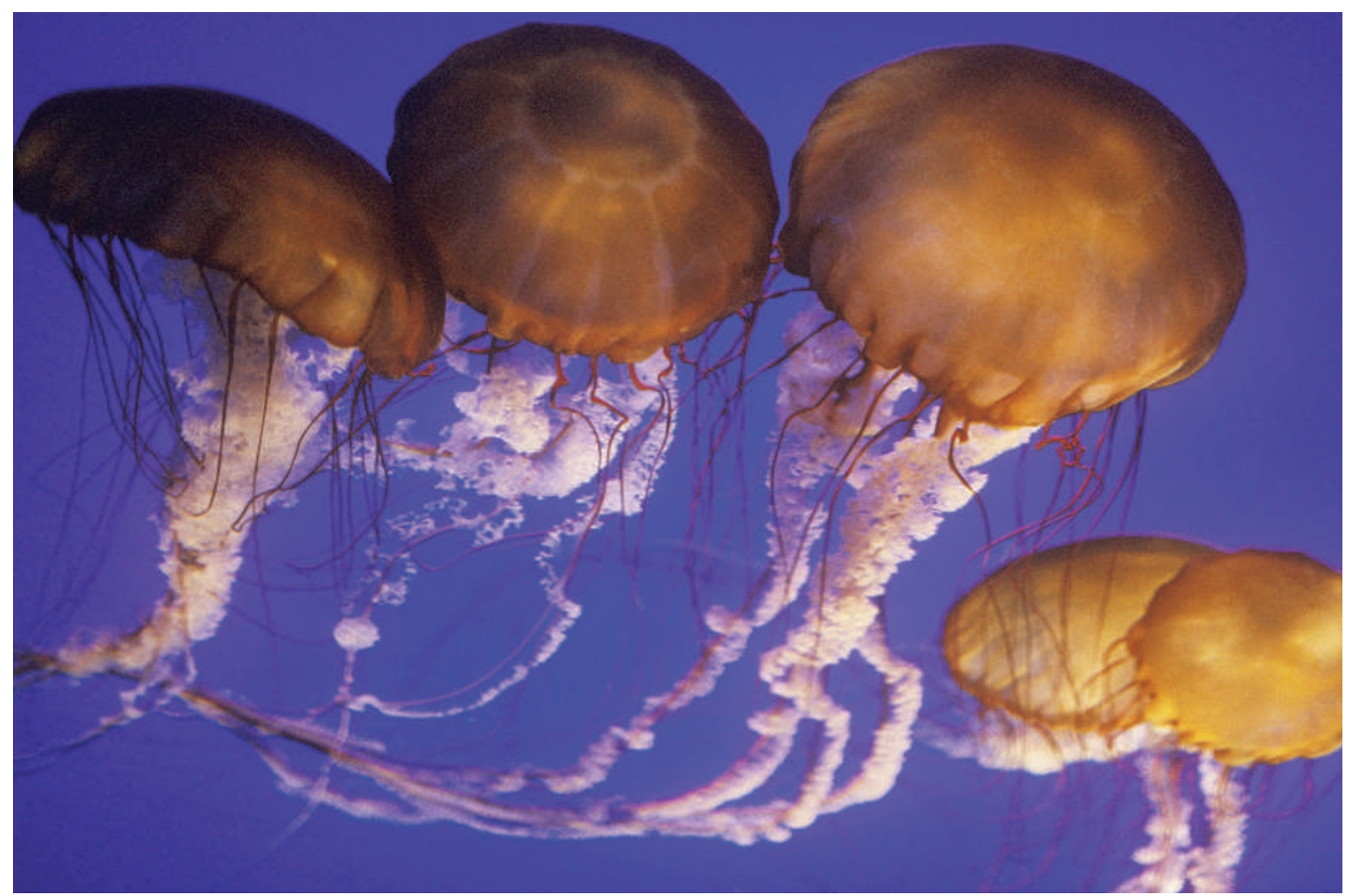

Even the simplest animal nervous systems, such as those of jellyfish, can spring suprises. 